\title{
Gun-Cotton and Other Explosive Agents
}

\section{F. A. Abel Esq., F.R.S.}

To cite this article: F. A. Abel Esq., F.R.S. (1866) Gun-Cotton and Other Explosive Agents, Royal United Services Institution. Journal, 10:40, 417-425, DOI: 10.1080/03071846609417214

To link to this article: http://dx.doi.org/10.1080/03071846609417214

\section{曲 Published online: 11 Sep 2009.}

Submit your article to this journal 정

Џll Article views: 1

Q View related articles $\longleftarrow$ 


\title{
LECTCRE.
}

Friday, May 25th, 1866.

General H.R.II. THE PRINCE OF WALES, K.G., K.S.I., Vice-Patron, in the Chair.

\section{GUN-COTTON AND OTHER EXPLOSIVE AGENTS.}

\author{
By F. A. Ader, Esq., F.R.S., Chemist to the War Department.
}

\begin{abstract}
Anstract.
The changes which havo been effected in the composition of gunpowder since its first application as a propelling agent, have been limited to small variations in the proportion of its components. But the modifications which have, from time to time, been introduced into the details of its manufacture, e.g., the preparation of the ingredients, their incorporation, and the conversion of the mixture into compact masses (grains, \&c.) of different size and density, have been sufficiently important and successful to secure the fulfilment by gunpowder, in a more or Iess efficient manner, of the very various requirements of military science, and of different branches of industry.

The characteristics of gunpowder, as in explosive material of permanent character, the action of which is susceptible of great modification, are mainly ascribable to the peculiar properties of the oxidising agent-saltpetre. Frequent attempts have been made to replace this constituent of gunpowder by other nitrates (such as those of sodium, lead, and barium), but, although materials suitable for blasting operations have been thus prepared (such as soda-gunpowder, and barytic powder, or poudre saxifragine), all mixtures of this class, hitherto produced, have exhibited important defects, when compared with gunpowder manufactured for propelling purposes.

The well-known oxidising agent, chlorate of potash, which differs from saltpetre only in containing chlorine in the place of nitrogen, is

roL. $x$. $2 \mathrm{~F}$
\end{abstract}


far more energetic in its action upon oxidisable bodies than any of the nitrates. Thus, a mixture of chlorate of potash with charcoal alone, delagrates as violently as gunpowder, and is far more readily inflamed by percussion than the latter, while a mixture analogous to gunporder, containing chlorate of potash in place of saltpetre, detonates violently when struck with moderate force, and acts far too destructively, on account of the rapidity of its explosion, to admit of its safo employment in fire-arms.

Many years ago a mixture, known as German orı white gunpowder, and consisting of cllorate of potash, ferrocyanide of potassium, and sugar, was proposed, and tried witliout success, as a substitute for gunpowder, and since then, many preparations of similar character have been suggested for employment, either as blasting and mining agents, or for use in shells, or even for all the purposes to which gunpowder is employed. The most promising of these, claimed as discoveries by Mr. ITorsley and Dr. Ehrhardt, are mixtures of chlorate of potash with substances of permanent character and readily obtained, containing both carbon and hydrogen, such as tannic and gallic acids, and some linds of resins. 'I'hcse mixtures are much less violently detonating than most of the explosive mixtures containing chlorate of potash, while, if well prepared, they are decidedly more powerful as explosives than gunpowder. For blasting purposes, some of these mixtures probably possess decided advantages over ordinary blasting powder, and possibly they may also be susceptible of employment for sporting purposes ; but they are not applicable to fire-arms used for war purposes, because in order to ensure the requisite uniformity of action, the ingredients must be submitted to proper processes of incorporation, such as are applied to the manufacture of gunpowder, and this treatment, would render the mixtures far more violent, and consequently destructive, in their action upon fire-arms, than if they were used in the form of crude mixtures.

A comparatively very safe application of chlorate of potash to the production of a substitute for gunpowder was made about six years ago by a German chemical manufacturer, M. Hochstädter. Unsized (blotting) paper was thoroughly soaked in, and conted with a thin paste consisting of chlorate of potash, finely-divided charcoal, a small quantity of sulphide of antimony, and a little stareh, gun, or some similar binding material, water being used as the solvent and mixing. agent. The paper was rolled up very compactly and dried in that form. In this manner, very frm rolls of an explosive material are obtained, which burns with considerable violence in open air, and the propelling effect of which, in small arms, has occasionally been found greater than that of a corresponding charge of riflo powder. Moreover, the material, if submitted in small portions to violent percussion, exhibits but little tendency to detonation. But, as no reliance could be placed on a sufficient uniformity of action in. a fire-arm, of these explosive rolls, this alone sufficed to prevent their competing with pewder. The same description of explosive preparation, differing only from that of M. Hochstälter in a trifling modification of its compasition, which is certainly not likely to lead to its greater success, has 
recently been brought forward in this country by M. Reichen and T. W. Melland.

One or two other much cruder explosive preparations, containing chlorate of potash, alone or in conjunction with saltpetre, have received some application to blasting purposes. One of these consisted of spent tan, in small fragments, which was saturated with the oxidising agent, and afterwards dusted over with sulphur. When flame or a red-hot iron is applied to this preparation, it deflagrates very slowly and imperfectly, but when cmployed in blast-holes, where it is confined within a small space, it derelopes sufficient explosive force to do good work. In addition to comparative cheapness, the great advantage of safety was claimed for this material by its inventor-a claim which was substantiated by the partial destruction by fire, on two occasions, of a manufactory of the substance near Plymouth, without the occurrence of an explosion.

One of the most remarkable materials recently employed to replace gunpowder as a destructire agent, is nitroglycerine. 'This substance was discovered by Sobrero in 1817, and is produced by adding glycerine in successive small quantities to a mixture of one volume of nitric acid of specific gravity $1 \cdot 43$, and two volumes of sulphuric acid, of specific gravity 1.83. The acid is cooled artificially during the addition of glycerine, and the mixture is afterwards poured into water, when an amber-coloured oily fluid separates, which is insoluble in water, and possesses no odour, but has a sweet, pungent flavour, and is very poisonous, a minute quantity, placed upon the tongtie, producing violent headache, which lasts several hours. The liquid has a specific gravity of $\mathbf{1 \cdot 6}$, and solidifies at about $5^{\circ} \mathrm{C}$. $\left(40^{\circ} \mathrm{F}\right.$.) If flame is applied, nitroglycerine simply burns, and if placed upon paper or metal, and held over a source of heat, it explodes feebly after a short time, burning with a smoky flame. If paper, moistened with it, be sharply struck, a somewhat violent detonation is produced.

Alfred Nobel, a Swedish engineer, was the first to attempt the application of nitroglycerine, as an explosive agent, in 180̈4. Some experiments were, in the first instance, made with gunpowder, the grains of which had bcen saturated with nitroglycerine. This powder burned much as usual, but with a brighter flame, in open air. When confined in shells or blast-holes, greater effects were, howerer, produced with it than with ordinary gunpowder; its destructire action is described as having been from three to six times greater than that of powder. The liquid could not be employed as a blasting agent in the ordinary manner, as the application of flame to it from an ordinary fuze, would not cause it to explode. But Mr. Nobel has succeeded, by employing a special description of fuze, in applying the liquid alone as it very powerful destructive agent. The cliarge of nitroglscerine having been introduced, in a suitable case, into the blast-hole, a fuze, to the extremity of which is attached a small charge of gunporrder, is fixed immediately over the liquid. The concussion produced by the exploding powder upon ignition of the fuze, effects the cxplosion of the nitroglycerine. The destructive action of this material is estimated, by those who have made experiments in London and Germany, 
at about ten times that of an equal weight of gunpowder. Therefore, although its cost is about seren times that of blasting powder, its use is stated to bo attended with considerable cconomy, more especially in hard rocks, a great saving being effected by its means in the labour of the miners and in the time occupied in performing a given amount of work, as much fewer and smaller blast-holes are required than when gunpowder is emplojed. The material appears to have recently received considerable application in some parts of Germany and in Sweden; but, in England, its employment has been confined to one set of experiments instituted in Cornmall last sunmer, upon which occasion a wrought-iron block, weighing about $3 \mathrm{crt}$., was rent into fragments by the explosion of a charge of less than ono ounce of nitroglycerine, placed in a central cavity.

Nitroglycerine appears therefore to possess very important advantages over gunpowder as a blasting and destructive agent, but the attempts to introduce it as a substitute for gunpowder hare already been attended by most disastrous results, ascribable in part to some of its properties and the erident instability of the commercial product; but principally to the thoughtlessness of those interested in its application, who appear to have been induced, either by undue confidence in its permanenco and comparative safety, or from less excusable motives, to leavo the masters of ships, or others who had to deal with the transport of the material, in ignorance of its dangerous character.

The precise causes of the fearful explosions of nitroglycerine which occurred at Aspinwall and San Francisco will, in all probability, never be ascertained, but they are likcly to have been due, at any rate indirectly, to the spontaneous decomposition of the substance, induced or accelerated by tho elevated temperature of the atmosphere in those parts of the. ships where it was stored. Instances are on record in which the riolent rupture of closed vessels containing commercial nitroglycerine has been occasioned by the accumulation of gases, generated by its gradual decomposition; and it is, at any rate, not improbable that a similar result, faroured by the warmth of the atmosphere, and eventually determined by some accidental agitation of the contents of a package of nitroglycerine, was the cause of those lamentable accidents. The great difficulties attending the purification of nitroglycerine upon a practical scale, and the uncertainty as regards stability of the material, even when purified (learing out of consideration its rery poisonous character and its extreme sensitiveness to explosion by percussion in the solid form), appenr to present insurmountable obstacles to its safe application as a substitute for gunporrder.

'The conrersion of purified lignin, or wood-fibre, into an explosive substance of the same nature as gun-cotton, was accomplished by chemists soon after Schönbein's discovery of gun-cotton was made known. Finely-divided rood or sardust may, by treatment with suitable agents, bo to a very considerable extent purified of substances foreign to cellulose, and if then submitted to careful treatment with a mixture of the strongest nitric and sulphuric acids, and properly purified, it furnishes a highly explosive material similar to the most explosive 
gun-cotton, and possessed, apparently, of considerable stability. Captain Schultze, a Prussian artillery oflicer, who was entrusted by his Government, a few years ago, with the inrestigation of gun-cotton, appears to have come to the conclusion that finely-divided wood offered greater prospect of conversion into a controlable explosive agent than cotton-wool. The ultimate results of his investigations has been the froduction of a "gun-sawclust,". the explosive properties of which depend in great measure upon its impregnation with a considerable proportion of an oxidising agent, either saltpetre or a mixture of that salt and nitrate of baryta. The wood having been reduced to a toleralbly uniform state of division, is submitted by Captain Schultze to purilying processes, for the separation of resinous and other substances from the lignin, and the product is converted, by digestion in a mixture of sulphuric and nitric acids, into a very feebly-explosive material, which leaves a considerable carbonaceous residue when burned. IThis product, after purification, is impregnaied with a sufficient proportion of nitrates to give it rapidly explosire power, the oxidation of the carbon being now almost complete.

The objects which appear to be aimed at by Captain Schultze in following this method of manufacturing a. wood-gunpowder, are, the production of a more gradually explosive material than is obtained by the most perfect action of nitric acid upon wood-fibre, and the possibility of preserving the material in a slightly explosive and therefore comparatively harmless form, nntil it is required for use, when it may be soon reudered powerfully explosive by impregnation with the nitrates. It is asserted that this powder is considerably moro powerful than gunpowder as a mining agent, and that by its employment in mines, the operators are enabled to return to work sooner than when gunpowder is used, because there is little or no smoke produced by its cxplosion. 'The latter is an undoubted advantage, which Schultze's powder shares with gun-cotton. Advantages are also claimed for this inaterial when employed in fire-arms, and it is possible that, when applied to sporting purposes, it may compete successfully with gunpowder in this direction also; but its behaviour as an explosive, and the peculiarities of its structure, afford little promise of its advantageous employment in arms for military and naval purposes.

Important progress has been made in the history and the practical application of gun-cotton since its study was resumed in this country, about three years ago. Very consideralule quantities of the material have been manufactured at the works of Micssrs. Prentice, at Stowmarket, and at the Government gunpowder works at Waltham Abbey. Its application to mining and artillery purposes and to small arms has been, and is still, the subject of systematic experiments, conducted by the Government Committee on Gun-cotton; its employment as a blasting agent is steadily increasing in sevcral important English mining districts; and considerable, though not uniform, success has already attended the employment of gun-cotton cartridges for sporting purposes.

The system of inanufacture of gun-cotton, as perfected by Baron von Lenk, has undergono but trifling modifications in its employment in this country. It has been made the subject of careful incestigation by 
Mr. Abcl; and the results furnished by many experimental manufacturing operations, and an examination of the products, have shown that the processes of converting cotton into the most explosive form of pyroxylin or gun-cotton, and of purifying the material, have been so greatly perfected by $\vee$. Lenk as to render a strict adherence to his simple and precise instructions alone necessary to ensure the preparation of very uniform products, which exhibit in their composition a very much closer approximation to purity than those obtained in the earlier days of the history of gun-cotton.

Althongh the conclusions arrived at by the many chemists who inrestigated the composition of gun-cotton soon after Schönbein's discovery varied very considerably, the constitution has been very generally regarded as definitely established by the researches of IIadow, published in 1854. According to that chemist, the most explosive guncotton has the composition expressed by the formula $\theta_{6} \Pi_{7} N_{3} \theta_{11}$ (which was first assigned to the substance by Mr. Orum in 1847), and may be regarded as cellulose, in which three atoms of hydrogen are replaced by threo molecules of peroxide of nitrogen. The name trinitro-cellulose has therefore been assigned to gun-cotton, its constitution being expressed by the formula $\theta_{6}\left\{\frac{H_{7}{ }^{\prime}}{3 \theta_{2}}\right\} \theta_{6}$.

Indow's conclusions have since been confirmed by other chemists, more especially by Redtenbacher, Schrötter, and Schneider, who have analysed specimens of gun-cotton prepared under v. Lenk's directions. But a report upon the Austrian gun-cotton was published, in 1861, by Pelouze and Maury, in which the formuln $\mathrm{E}_{24} \mathrm{H}_{36} \theta_{13}, 5 \mathrm{~N}_{3} \theta_{5}$ is assigned to the product of $r$. Lenk's process, the conclusions of those chemists being founded partly upon some analytical results and partly upon the increase of weight which they found cotton to sustain, when submitted to treatment with the mixed acids. They observed the greatest increase in weight to be 78 per cent., a number slightly in exccss of that which would correspond to the requirements of the formula which they adopt.

An experimental inquiry into the composition of gun-cotton, as obtained by v. Lenk's process has been instituted by MIr. $\Lambda$ bel, and the very numerous analytical and synthetical results which he had obtained, confirm the correctness of the formula assigned by Crum and Hadow to the most explosive gun-cotton, and demonstrate satisfactorily that the products obtained by following strictly the instructions given by $v$. Lenk, are inrariably trinitro-cellulose, in a condition as nearly approaching purity as a manufacturing operation can be expected to furnish.

The most explosivo gun-cotton is perfectly insoluble in mixtures of ether and alcohol; but, by varying tho proportions and strength of the acids employed for the conversion of cotton, products of less explosive character are obtained, which are more or less freely soluble in ether and alcohol (furnishing the well-known material collodion). If, therefore, in manufacturing gun-cotton, the conditions essential to the production of insoluble pyroxylin are not most strictly fulfilled, the uniformity of the product will suffer. 
The ordinary products of manufacture are never altogether frec from soluble ginn-cotton, but the proportion present is small and very uniform, amounting to about 1.5 per cent. They contain, besides, a small quantity (about 1.5 per cent.) of matter soluble in alcohol alone, and possessed of acid characters, which is evidently produced by the action of nitric acid upon such small quautities of resinous or other matters foreign to pure cellulose as are not completely removed from the cotton fibre by the purification which it receires. There appears good reason to believe that this impurity in gun-cotton is of comparatively unstable character, and that the great proneness to spontaneous decomposition, which has been observed by Pelouze and Maury, De Luca, and others, in some specimens of gun-cotton, is to be ascribed in great measure to the existence, in those specimens, of comparatively large proportions of these unstable bye-products.

One hundred parts of carefully purified cotton-wool hare been found by $\mathrm{Mr}$. Abel to furnish from 181.8 to 182.5 parts of gun-cotton. 'The increase which perfectly pure cellulose should sustain by absolutely complete conversion into a substance of the formula $\epsilon_{6} \mathrm{H}_{7} \mathrm{~N} \theta$ (trinitrocellulose) is 83.3 ; the above results are, therefore, strong confirmations of the correctness of this generally accepted view of the composition of gum-cotton. In carrying out the actual manufacturing process as prescribed by $r$. Lenk, somewhat lower results are obtained, because of impurities existing in the cotton employed, and of loss of product during its purification.

Very extensive experiments are in progress at Woolwich with the view of cxamining fully into the extent of liability to change of guncotton, when preserved in-store, or exposed for prolonged periods to light, and to degrees of heat ranging betwcen the ordinary atmospheric temperatures and that of boiling water. 'The results' hitherto arrived at, though they have shown that, under very sercro conditions, gumcotton is liable to decompose, have not confirmed the conclusions arrived at by the French chemists with regard to the great instability of the material. Thus, De Luca states all specimens exposed by him to sunlight decomposed either on the first day, or within a few days. But, at Woolwich, no single instance of such rapid decomposition of gun-cotton made by the present process has been noticed.

A very gradual and slight development of gas occurs after a time, when the substance is exposed to sunlight, but the quantity which has been collected from specimens exposed at Woolwich to direct day and sun light for $2 \frac{1}{2}$ years is very small, and the gun-cotton has in all instances preserved its original appearance. Pelouze and Maury state that gun-cotton almays decomposes perfectly within a fer day's by exposure to temperatures of $55^{\circ}-60^{\circ} \mathrm{C} .\left(130^{\circ}-140^{\circ} \mathrm{F}\right.$.), and they lay great stress upon the explosion of a specimen directly it was introduced into a vessel heated to $47^{\circ} \mathrm{C}$. $\left(116^{\circ} \cdot 6 \mathrm{~F}\right.$.). But at Woolwich a specimen of ordinary produce, which has been exposed now for 12 . months to $65^{\circ}$ C. $\left(150^{\circ} \mathrm{F}\right.$.), has evolved only a small quantity of gas, and retains its original appearance perfectly. Several specimens, after having been exposed for some days to a temperature of $90^{\circ} \mathrm{G}$. ( $\left(191^{\circ} \mathrm{F}.\right)$, duringwhich period some nitrous vapours were in all instances erolved, have 
since been exposed to light in closed vessels for about 20 months, and still retain their original appearanco and explosire charncters.

Several large ammunition cases, closcly packed with gun-cotton, have been preserred for six months in a chamber, tho temperature of which was maintained for three months at $49^{\circ} \mathrm{C}$. $\left(120^{\circ} \mathrm{F}\right.$.), and afterwards at $51-55^{\circ} \mathrm{C} .\left(130^{\circ} \mathrm{F}.\right)$, arrangements having been made for periodically registering the temperature mithin the boses, which wero kept closed. In no instance has the latter temperaturo risen to an extent to indicato serious chemical change, i.e., it lias alrays been below the temperature of the air in the clummber. These few examples of results already obtained are given to show that the belaviour of gun-cotton manufactured in England by v. Lenk's process does not as yet at all justify the condemnation which tho material has recently received in France.

One most important point in connection with the preservation of gun-cotton appears to havo been lost sight of by the French experimenters. The material may be most perfectly preserred, apparently, for any period, either by immersion in water, or, still more simply, by being impreguated with just sufficient moisture to render it perfectly uninflammable. In this condition gun-cotton is much safer than gunpowder can be rendered by mixture even with rery large proportions of incombustible materials. It may bo transported with quite as much safety as the unconverted cotton; indeed, it appears to be very much less prone to gradual decay, if preserved for very long periods in a damp condition, than cotton or nther vegetablo substances. Numerous specimens of gun-cotton, preserved for many months in a very damp chamber, torether with paper, cotton fabrics, and wood, retained their strength of fibre and all the original propertics, and had no signs even of mildew upon them; whilo the paper and fabrics, in immediate contact with it, had completely rotted away, and the wood was covered with fungi.

Considerable progress has been made in the manipulation of guncotton, with the object of modifying its explosive action. The rapidity with which gun-cotton burns in open air admits of ready and very considerable variation, by applying the simple expedients of winding, twisting, or plaiting gun-cotton yarn of different sizes. But although a mass of gun-cotton many be made to burn in a comparatively gradual manner by being very tightly wound, a charge of tho material, in that form, acts quite as destructirely, when exploded in the bore of a gun, as an equal charge consisting of the yarn wound very loosely, because the pressure of gas established by the first ignition of the charge renders the compact packing of the gun-cotton powerless to resist the instantaneous penetration of flame between the separate layers of the material. The assertion that a power had been acquired of controlling the explosive action of gun-cotton in a fire-arm, by simply varyirg the compactness with which the material was twisted or wound, has therefore proved quite crroneous.

There are, however, two methods of reducing the rapidity of explosion of gun-cotton, which are much more likely to furnish successful results. The one consists in diluting the material, by its admixture 
either with a less explosive variety of gun-cotton, or with some unexplosive substance, such, for instaice, as the cotton in its original form. The latter mode of dilution has recently been applied by Messrs. Prentice to the construction of cartridges for sporting purposes, and they describe the results already arrived at as rery promising. The second method of controlling the explosion of gun-cotton consists in consolidating the material, by pressure, into compact homogencous masses, and in confining tho first ignition of such compressed guncotton in the bore of the guns to certain surfaces.

The gun-cotton fibre, in the form of yarn or plait, may be compressed into very compact masses, by being rammed into strong cylinders of pastcboard or other suitable material, but much more perfectly homogeneous and solid masses are produced, independently of cylinders or other cases, by a method which $\mathrm{BI}$. A $A$ bel has recently claborated, and which consists in reducing tho gun-cotton fibre to a fine state of division, or pulp, as in the process of paper-making, and in converting this pulp by pressure into solid masses of any suitable form or density. r'his mothod of operating affords also special facilities for combining both methods, dilution and compression, of reducing the explosive violence of gun-cotton. The material is, in fact, operated upon by this system in a manner exactly corresponding to the processes by which the explosise action of gumporder is regulated to so remarkable an extent. Some results, which are admitted by the most sceptical as encouraging, have already been arrived at in the systematic courso of experiments which are in progress, with the object of applying the methods of regulation pointed out, to the reduction of gun-cotton to a safe form for artillery purposes.

Its arrangement in a form suitable for small arms is a much less difficult problem, which may be considered as approaching a perfect solution. For employment in shells and for military mines, both land and submarine, the compressed or solid form of gun-cotton presents special advantages, on account of the great compactness which may be imparted to it; a giren weight, arranged so as to ignite instantancously under pressure (i.e., in strong vessels), may be made to occupy the same space as an equal weight of gunpowder, whereas the forms of gun-cotton litherto applied to these purposes occupy about three times the space of gunpowder.

Beautiful pyrotechnic effects may be readily produced by means of gun-cotton, thongh the absence of smoke, which in some of its applieations (especially in mines) wonld constitute an important advantage, detracts from some of the effects which may be obtained with ordinary pyrotechnic compositions. On the other haud, gun-cotton fireworks may be displayed indoors without inconvenience.

'There appears at present no reason to doubt that the application of gun-cutton, with great advantage to at least some of the inore important purposes for which gunpowder is used, will, ere long, be fully established, and that this interesting explosive agent is destined to occupy a permanent and prominent position among the most important products of chemical industry. 